\title{
Studies on the Nature of Propagating Species in Cationic Polymerization of Isobutyl Vinyl Ether by Iodine
}

\author{
Toshiyuki OHTORI, Yoshitsugu HIROKAwA, \\ and Toshinobu HIGASHIMURA \\ Department of Polymer Chemistry, Kyoto University, \\ Kyoto 606, Japan.
}

(Received September 18, 1978)

\begin{abstract}
In order to elucidate the nature of the propagating species in cationic polymerization, isobutyl vinyl ether was polymerized by iodine in solvents of different polarities, both in the presence and absence of a common-ion salt (tetra- $n$-butylammonium tri-iodide). The molecular weight distribution (MWD) of polymers produced in salt-free methylene chloride at $0^{\circ} \mathrm{C}$ was broad. With increasing salt concentration, the amount of high-molecular-weight polymer decreased, and the MWD was very similar to that for the polymers produced in carbon tetrachloride. The polymerization rate was also reduced by the salt and approached a constant value. These results indicate the existence of two kinds of propagating species in different dissociation states in methylene chloride: dissociated and non-dissociated species. In spite of the existence of the two propagating species, however, the polymers did not show a bimodal MWD in methylene chloride. This, coupled with the uniformity in tacticity of the polymers, suggests a rapid exchange between the two species. For comparison, polymerizations with acetyl perchlorate were carried out in a variety of solvents.

KEY WORDS Isobutyl Vinyl Ether/Iodine / Acetyl Perchlorate / Cationic Polymerization / Propagating Species / Common-Ion Salt / Molecular Weight Distribution / Steric Structure /
\end{abstract}

In the cationic polymerization of styrene by acetyl perchlorate ${ }^{1,2}$ or trifluoromethanesulfonic acid $^{3,4}$ and of $p$-methoxystyrene by iodine, ${ }^{5}$ the produced polymers show a bimodal molecular weight distribution (MWD) in solvents of suitable polarity. The addition of common-ion salts to these polymerization systems suppresses the polymerization rate and the production of higher-molecular-weight polymers. We have interpreted these facts to be due to the coexistence of two kinds of propagating species in different dissociation states.

In the polymerization of vinyl ethers, on the other hand, the coexistence of such different species has not been shown yet, although the effect of solvent polarity on the steric structure and molecular weight of polymers suggests their presence. Since changing the solvent polarity is sometimes accompanied by complications such as selective solvation, it is desirable that the dissociation state of the propagating species be varied in the same solvent. Addition of a neutral salt (common-ion salt) having the same counteranion as that of the propagating species may fulfill this requirement. However, there has been only one report concerning the common-ion effect on the cationic polymerization of vinyl ethers. Kunitake, et $a l .{ }^{6}$ studied the steric structure of poly(isobutyl vinyl ether) formed by $\left(\mathrm{C}_{6} \mathrm{H}_{5}\right)_{3} \mathrm{C}^{+} \mathrm{SnCl}_{5}{ }^{-}$in the presence of the corresponding tetrabutylammonium salt; the steric structure was affected only slightly by the added salt.

In the present study, we investigated the effects of both solvent polarity and common-ion salts on the polymerization of isobutyl vinyl ether (IBVE) to discuss the dissociation state of the propagating species derived from vinyl ethers. Iodine was used as an initiator which would give a highly nucleophilic counteranion that would interact strongly with a relatively stable propagating carbocation derived from IBVE. Our previous work ${ }^{7}$ with styrene derivatives indicates that a combination of a nucleophilic counteranion and a stable carbocation is preferred for the coexistence of the two propagating 
species. For comparison, acetyl perchlorate $\left(\mathrm{AcClO}_{4}\right)$, which produces a less nucleophilic counteranion, was also used as the initiator.

\section{EXPERIMENTAL}

\section{Materials}

Monomer and Solvents. Commercial IBVE was washed with aqueous sodium hydroxide solution and then with water, and was distilled twice over calcium hydride before use. The purity of the monomer was found to be more than $99.9 \%$ by gas chromatography. Solvents (methylene chloride, carbon tetrachloride, toluene, and hexane) and an internal standard for gas chromatography (octane) were purified as reported in a previous paper. ${ }^{2}$

Initiators and Salts. Iodine (Merck, Guaranteed Reagent) was used without further purification. $\mathrm{AcClO}_{4}$ was synthesized from silver perchlorate and acetyl chloride as described elsewhere. ${ }^{8}$ Tetra- $n$ butylammonium iodide $\left(\mathrm{Bu}_{4} \mathrm{NI}\right)$ and tetra- $n$-butylammonium perchlorate $\left(\mathrm{Bu}_{4} \mathrm{NClO}_{4}\right)$ were commercially obtained (Wako Pure Chemicals, Guaranteed Reagent), and were dried in vacuo before use. Tetra$n$-butylammonium tri-iodide $\left(\mathrm{Bu}_{4} \mathrm{NI}_{3}\right)$. was synthesized from $\mathrm{Bu}_{4} \mathrm{NI}$ and iodine. ${ }^{9}$

\section{Procedures}

Polymerization was carried out in an Erlenmeyer flask equipped with a three-way stopcock under dry nitrogen. The reaction was initiated by adding an initiator solution to a monomer solution, and terminated after a certain period by addition of methanol or isopropanol containing a small amount of ammonia. Conversion was determined by measuring the residual monomer concentration by means of gas chromatography.

In the polymerization by iodine, the reaction mixture after quenching was washed with aqueous sodium thiosulfate solution to remove the unreacted initiator, and was evaporated to dryness to give the product polymers, which were then dried in vacuo. The polymers produced by $\mathrm{AcClO}_{4}$ were precipitated into an excess of methanol, isolated by decantation, and dried in vacuo. The MWD of these polymers was measured by gel-permeation chromatography (GPC) on a Shimadzu Model GPC-700 equipped with five columns of polystyrene gel (SG-1, 2, 3, 4, and 5) (eluent, methyl ethyl ketone; at ambient temperature). As the relation between the elution volume and the molecular weight of poly(IBVE) is not known, the latter was approximately assessed from that of polystyrene corresponding to the same elution volume. This molecular weight value is represented as $(\mathrm{MW})_{\mathrm{s}}$ in this paper. The steric structures of the polymers were compared on the basis of their precipitation temperatures $\left(T_{\mathrm{p}}\right)$ in methyl ethyl ketone $(0.5 \mathrm{w} / \mathrm{v} \%$ solution) ${ }^{6.10}$

\section{RESULTS}

Effect of Solvent Polarity on the Polymerization Rate and the Molecular Weight and Molecular Weight Distribution of Polymers

IBVE was polymerized by iodine at $0^{\circ} \mathrm{C}$ in solvents of different polarities. Figure 1 shows typical time-conversion curves. They are sigmoidal and the

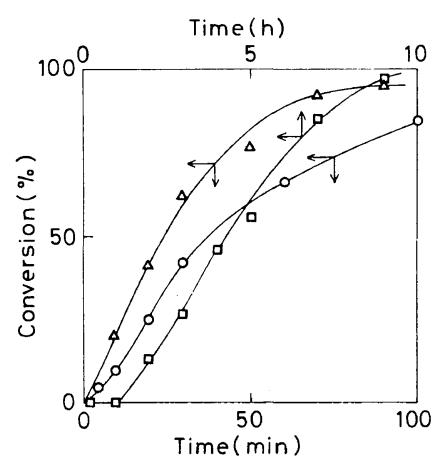

Figure 1. Effect of solvents on time-conversion curves in the polymerization of IBVE at $0^{\circ} \mathrm{C} ;[\mathrm{M}]_{0}=0.38 \mathrm{M}$. Solvent: $\bigcirc, \mathrm{CH}_{2} \mathrm{Cl}_{2},\left[\mathrm{I}_{2}\right]_{0}=0.33 \mathrm{mM} ; \triangle, \mathrm{CH}_{2} \mathrm{Cl}_{2} / \mathrm{CCl}_{4}$ $(2 / 1 \mathrm{v} / \mathrm{v}),\left[\mathrm{I}_{2}\right]_{0}=2.0 \mathrm{mM} ; \square, \mathrm{CCl}_{4},\left[\mathrm{I}_{2}\right]_{0}=5.0 \mathrm{mM}$.

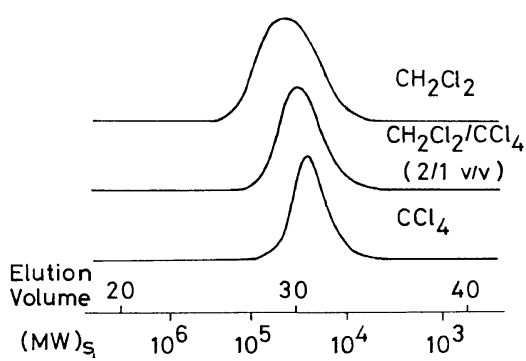

Figure 2. Effect of solvents on the MWD of poly(IBVE) obtained with iodine at $0^{\circ} \mathrm{C}$ (conversion, $55-60 \%$ ). Polymerization conditions are the same as in Figure 1. 
induction period increased with a decrease of solvent polarity. After the induction period, the polymerization rate was of first order with respect to the monomer. The maximum polymerization rate was of second order with respect to the initial concentration of iodine, and increased with an increase of solvent polarity.

Figure 2 illustrates the MWD of the polymers obtained with iodine in three solvents at $0^{\circ} \mathrm{C}$. The MWD was always unimodal. The distribution for methylene chloride was fairly broad independent of catalyst concentration and the MWD became narrower as the solvent polarity decreased.

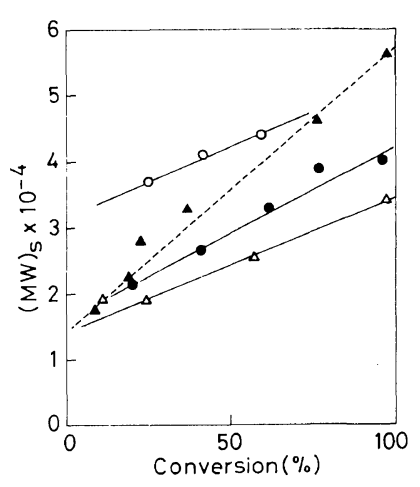

Figure 3. Relation between monomer conversion and the molecular weight $\left((\mathrm{MW})_{\mathrm{s}}\right)$ of poly(IBVE) obtained with iodine: $[\mathrm{M}]_{0}=0.38 \mathrm{M}$; polymerization temp, solid line, $0^{\circ} \mathrm{C}$; broken line $-78^{\circ} \mathrm{C}$. Solvent: $\bigcirc, \mathrm{CH}_{2} \mathrm{Cl}_{2}$, $\left[\mathrm{I}_{2}\right]_{0}=0.33 \mathrm{mM} ; \quad \bigcirc, \quad \mathrm{CH}_{2} \mathrm{Cl}_{2} / \mathrm{CCl}_{4} \quad(2 / 1 \quad \mathrm{v} / \mathrm{v})$, $\left[\mathrm{I}_{2}\right]_{0}=2.0 \mathrm{mM} ; \triangle, \mathrm{CCl}_{4},\left[\mathrm{I}_{2}\right]_{0}=10 \mathrm{mM} ; \Delta, \mathrm{CH}_{2} \mathrm{Cl}_{2}$, $\left[\mathrm{I}_{2}\right]_{0}=5.0 \mathrm{mM}$.

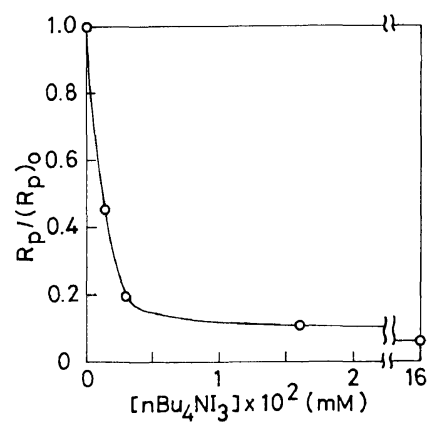

Figure 4. Effect of $\mathrm{Bu}_{4} \mathrm{NI}_{3}$ on the polymerization rate of IBVE by iodine in $\mathrm{CH}_{2} \mathrm{Cl}_{2}$ at $0^{\circ} \mathrm{C}:[\mathrm{M}]_{0}=0.38 \mathrm{M}$; $\left[\mathrm{I}_{2}\right]_{0}=0.33 \mathrm{mM} . R_{\mathrm{p}}$ and $\left(R_{\mathrm{p}}\right)_{0}$ represent the maximum rates in the presence and absence of the salt, respectively.
Figure 3 shows plots of the polymer molecular weights $\left((\mathrm{MW})_{\mathrm{s}}\right)$ against conversion for the polymerizations in various solvents. The $(\mathrm{MW})_{\mathrm{s}}$ was determined from the peak position of the MWD curves. In all the solvents, the $(\mathrm{MW})_{\mathrm{s}}$ linearly increased with conversion.

In the polymerization at $-78^{\circ} \mathrm{C}$, the polymerization rate increased with an increase of solvent polarity and a linear increase of $(\mathrm{MW})_{\mathrm{s}}$ with conversion was observed (Figure 3) like that at $0^{\circ} \mathrm{C}$. The $(\mathrm{MW})_{\mathrm{s}}$ at similar conversions and the shape of the MWD of the polymers varied a little with solvent polarity.

Effect of Common-Ion Salts on the Polymerization Rate and the Molecular Weight and Molecular Weight Distribution of Polymers

It is uncertain whether the counteranion is $\mathrm{I}^{-}$or $\mathrm{I}_{3}{ }^{-}$in the polymerization by iodine. ${ }^{11-13}$ In the present study, $\mathrm{Bu}_{4} \mathrm{NI}_{3}$ was mainly employed as a common-ion salt, because the polymerization rate in methylene chloride was of second order with respect to iodine concentration, as shown above. $\mathrm{Bu}_{4} \mathrm{NI}$ was also used for comparison.

As shown in Figure 4, the maximum polymerization rate, $R_{\mathrm{p}}$ (determined from the maximum slope of a time-conversion curve), in methylene chloride was greatly reduced by the addition of only a small amount of $\mathrm{Bu}_{4} \mathrm{NI}_{3}(1 / 100-1 / 200$ of iodine concentration). However, on further addition of the salt, $R_{\mathrm{p}}$ did not change significantly and apparently reached a constant value. The effect of $\mathrm{Bu}_{4} \mathrm{NI}$ on $R_{\mathrm{p}}$ was slightly smaller than that of $\mathrm{Bu}_{4} \mathrm{NI}_{3}$.

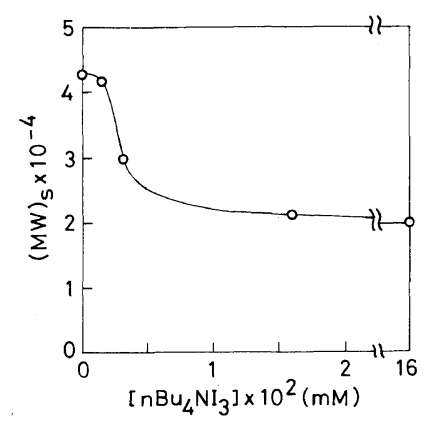

Figure 5. Effect of $\mathrm{Bu}_{4} \mathrm{NI}_{3}$ on the molecular weight $\left((\mathrm{MW})_{\mathrm{s}}\right)$ of poly(IBVE) obtained with iodine (conversion, $50 \%$ ). Polymerization conditions are the same as in Figure 4. 


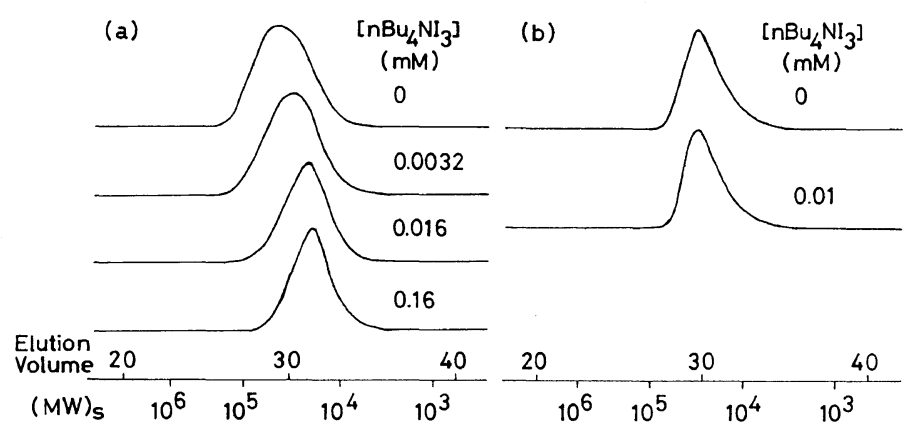

Figure 6. Effect of $\mathrm{Bu}_{4} \mathrm{NI}_{3}$ on the MWD of poly(IBVE) obtained with iodine at $0{ }^{\circ} \mathrm{C} ;[\mathrm{M}]_{0}=0.38 \mathrm{M}$. Solvent: (a) $\mathrm{CH}_{2} \mathrm{Cl}_{2},\left[\mathrm{I}_{2}\right]_{0}=0.33 \mathrm{mM}$, conversion, $50-60 \%$; (b) $\mathrm{CCl}_{4},\left[\mathrm{I}_{2}\right]_{0}=10 \mathrm{mM}$, conversion, $95-100 \%$.

Figure 5 shows the relation between $\mathrm{Bu}_{4} \mathrm{NI}_{3}$ concentration and the molecular weight $\left((\mathrm{MW})_{\mathrm{s}}\right)$ of the polymers obtained in methylene chloride at $0^{\circ} \mathrm{C}$ at about $50 \%$ conversion. The $(\mathrm{MW})_{\mathrm{s}}$ steeply decreased on addition of the common-ion salt, and then approached a constant value. The effect of $\mathrm{Bu}_{4} \mathrm{NI}$ was smaller than that of $\mathrm{Bu}_{4} \mathrm{NI}_{3}$.

The MWD of the polymers obtained in the presence of $\mathrm{Bu}_{4} \mathrm{NI}_{3}$ at $0^{\circ} \mathrm{C}$ is shown in Figure 6 . In methylene chloride the MWD became progressively narrower with increasing salt concentration, and finally a sharp distribution similar to that in nonpolar solvents (see Figure 2, c) was observed. These changes correspond to those in $R_{\mathrm{p}}$ shown in Figure 4. It should also be noted that salt addition in a polar solvent (methylene chloride) and decreasing solvent polarity induced the same effect on the MWD of polymers ( $c f$., Figures 2 and 6). On the other hand, in nonpolar solvents such as carbon tetrachloride, the common-ion salt did not affect both the MWD (Figure 6, b) and the polymerization rate.

In the polymerization at $-78^{\circ} \mathrm{C}$ the addition of the common-ion salt in methylene chloride slightly decreased the polymerization rate and $(\mathrm{MW})_{\mathrm{s}}$.

When $\mathrm{AcClO}_{4}$ was employed as an initiator, the polymerization in methylene chloride at $0^{\circ} \mathrm{C}$ was very fast (completed within $2 \mathrm{~min}$ ), and the produced polymers showed a broader MWD than that of the polymers formed by iodine under similar conditions. However, the peak molecular weight was nearly the same as that of the polymers obtained with iodine.

\section{The Steric Structure of Polymers}

Precipitation temperatures $\left(T_{\mathrm{p}}\right)$ of the polymers obtained at $0^{\circ} \mathrm{C}$ in methylene chloride and carbon tetrachloride were $-53^{\circ} \mathrm{C}$ and $-27^{\circ} \mathrm{C}$, respectively,

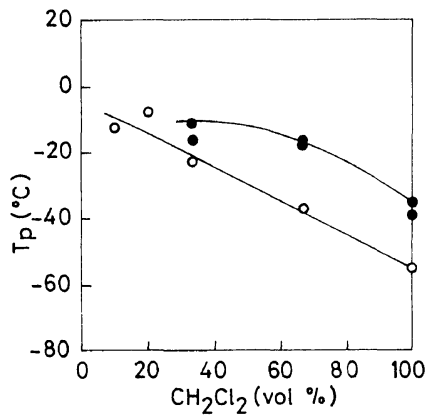

Figure 7. Effect of solvent polarity and $\mathrm{Bu}_{4} \mathrm{NI}_{3}$ on the precipitation temperature $\left(T_{\mathrm{p}}\right)$ of poly(IBVE) obtained with iodine at $-78^{\circ} \mathrm{C}$ in $\mathrm{CH}_{2} \mathrm{Cl}_{2}-\mathrm{C}_{6} \mathrm{H}_{5} \mathrm{CH}_{3}$ mixtures: $\bigcirc$, salt free; $\bigcirc\left[\mathrm{Bu}_{4} \mathrm{NI}_{3}\right]=0.20-10 \mathrm{mM} ;[\mathrm{M}]_{0}=0.38 \mathrm{M}$; $\left[\mathrm{I}_{2}\right]_{0}=20 \mathrm{mM}$.

and no fraction with $T_{\mathrm{p}}$ higher than $-53^{\circ} \mathrm{C}$ was found in the polymer obtained in methylene chloride. This fact indicates that polymers having high stereoregularity are not produced in methylene chloride.

Furthermore, in order to confirm that the nondissociated species produces the polymer with high $T_{\mathrm{p}}$ in the polymerization by iodine, the effect of common-ion salts was investigated. Since the poly(IBVE) prepared at $0^{\circ} \mathrm{C}$ is highly amorphous and the $T_{\mathrm{p}}$ is sensitive to the molecular weight rather than the steric structure of the polymer, the effect of the common ion on the steric structure was examined only for the polymers produced at $-78^{\circ} \mathrm{C}$.

Figure 7 shows the $T_{\mathrm{p}}$ of the polymers obtained by iodine at $-78^{\circ} \mathrm{C}$ in methylene chloride/toluene mixtures with various polarities. In the absence of the salt $\left(\mathrm{Bu}_{4} \mathrm{NI}_{3}\right)$, as already reported, ${ }^{10}$ a decrease of solvent polarity caused a rise in $T_{\mathrm{p}}$, indicating an 


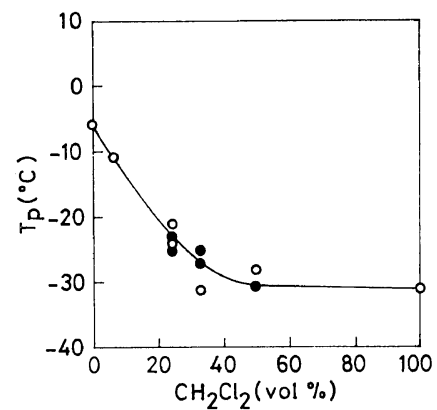

Figure 8. Effect of solvent polarity and $\mathrm{Bu}_{4} \mathrm{NClO}_{4}$ on the precipitation temperature $\left(T_{\mathrm{p}}\right)$ of poly(IBVE) obtained with $\mathrm{AcClO}_{4}$ at $-78^{\circ} \mathrm{C}$ in $\mathrm{CH}_{2} \mathrm{Cl}_{2}-\mathrm{C}_{6} \mathrm{H}_{14}$ mixtures: $\bigcirc$, salt free; $\bigcirc,\left[\mathrm{Bu}_{4} \mathrm{NClO}_{4}\right]=0.20-5.0 \mathrm{mM}$; $[\mathrm{M}]_{4}=0.38 \mathrm{M} ;\left[\mathrm{AcClO}_{4}\right]_{0}=0.10 \mathrm{mM}$.

increase of the isotacticity of the polymers. Addition of $\mathrm{Bu}_{4} \mathrm{NI}_{3}$ increased the $T_{\mathrm{p}}$ in methylene chloride and methylene chloride/toluene mixture. The extent of the $T_{\mathrm{p}}$ increase was greater in more polar solvents; the salt effect was not observed in nonpolar solvents. The $T_{\mathrm{p}}$ did not depend on the salt concentration, which ranged from 0.20 to $10 \mathrm{mM}$.

On the other hand, the $T_{\mathrm{p}}$ of the polymers obtained with $\mathrm{AcClO}_{4}$ at $-78^{\circ} \mathrm{C}$ was not affected by addition of a common-ion salt $\left(\mathrm{Bu}_{4} \mathrm{NClO}_{4}\right)$ (Figure 8). Even in a fairly polar solvent $\left(\mathrm{CH}_{2} \mathrm{Cl}_{2} / \mathrm{C}_{6} \mathrm{H}_{14}=1 / 1 \mathrm{v} / \mathrm{v}\right)$, the $T_{\mathrm{p}}$ was $c a$. $-30^{\circ} \mathrm{C}$ both in the absence and the presence of the salt.

\section{DISCUSSION}

In the present study, we have investigated how the suppression of dissociation of the propagating species, which is induced by an added common-ion salt without changing solvent polarity, affects the polymerization of IBVE.

In the polymerization of IBVE by iodine at $0^{\circ} \mathrm{C}$, as described above, the MWD of the product polymers in methylene chloride (polar solvent) was relatively broad, and this became progressively narrower with addition of a common-ion salt to give a sharp MWD that was very similar to the MWD for the polymers in carbon tetrachloride (nonpolar solvent) (Figure 6). Corresponding to this change, the molecular weight, $(\mathrm{MW})_{\mathrm{s}}$, of the polymers formed in methylene chloride decreased with increasing salt concentration and finally reached a constant value (Figure 5). The maximum polymerization rate, $R_{\mathrm{p}}$, was also reduced by a common-ion salt and approached a constant value (Figure 4). These trends indicate that in saltfree methylene chloride at least two propagating species coexist: one is suppressed by an added common-ion salt and the other predominates in the presence of the salt. As we have confirmed for the polymerization of styrene derivatives, ${ }^{1-5}$ the former should be a dissociated species and the latter a nondissociated species. In the polymerization at $-78^{\circ} \mathrm{C}$, the observed increase of the isotacticity $\left(T_{\mathrm{p}}\right.$ value) of polymers on salt addition (Figure 7) supports this, indicating that the counteranion is located nearer to the growing end in the presence of the salt than in its absence.

In spite of the existence of the two propagating species, the poly(IBVE) formed by iodine did not show a clear bimodal MWD. Since the bimodal MWD requires simultaneous and independent propagation of the two species, the absence of bimodality in MWD suggests the following possibilities: (i) the two species propagate independently without exchange, but produce polymers with similar molecular weights; (ii) the exchange between the two species is so rapid that they cannot propagate independently. If possibility (i) is correct, the polymers produced by the non-dissociated propagating species must have a higher isotacticity than that of the polymers produced by the dissociated species. However, the $T_{\mathrm{p}}$ of the whole polymer obtained in methylene chloride at $0^{\circ} \mathrm{C}$ was as low as $-53^{\circ} \mathrm{C}$, and our $T_{\mathrm{p}}$ measurement showed no evidence indicating the presence of a fraction with a higher $T_{\mathrm{p}}$ value (the $T_{\mathrm{p}}$ for the polymers produced in carbon tetrachloride was $-27^{\circ} \mathrm{C}$ ). These results suggest a rapid exchange of the propagating species in the IBVE polymerization. This may be due to the stability of the propagating species induced by their electrondonating alkoxy groups.

In the IBVE polymerization by iodine under various conditions, the molecular weight increased linearly with conversion (Figure 3). The slope of $(\mathrm{MW})_{\mathrm{s}}$ vs. conversion plots was larger at $-78^{\circ} \mathrm{C}$ than at $0^{\circ} \mathrm{C}$. Although the extent of the molecular weight increase is not large, these results suggest the possibility that a long-lived propagating species exists in the polymerization of IBVE by iodine, as in that of $p$-methoxystyrene by the same initiator in a nonpolar solvent. ${ }^{14}$ This possibility is now being investigated in our laboratories and the results will be published later. 
In the iodine-initiated polymerization at $-78^{\circ} \mathrm{C}$, the $T_{\mathrm{p}}$ of the polymers produced in methylene chloride clearly rose on addition of a common-ion salt, whereas no such increase in $T_{\mathrm{p}}$ was observed in the $\mathrm{AcClO}_{4}$-initiated polymerization. Since in both polymerizations the propàgating species must be an ion pair (non-dissociated species) in the presence of a large amount of common-ion salts, this suggests that the ion pair carrying $\mathrm{I}_{3}{ }^{-}$as counteranion and the one with $\mathrm{ClO}_{4}{ }^{-}$behave differently in the polymerization of IBVE. The ion pair carrying $\mathrm{I}_{3}{ }^{-}$may be tight because of the strong nucleophilicity of the counteranion and be very different in nature from the dissociated (free-ionic) species. The ion pair carrying $\mathrm{ClO}_{4}{ }^{-}$may be loose because of the weak nucleophilicity of the counteranion and thus be similar in nature to the dissociated species. Thus, it gave the polymers with the same $T_{\mathrm{p}}$ value as that for the polymers in salt-free methylene chloride. The presence of different ion-pair species has also been proposed by us for the styrene polymerization by $\mathrm{AcClO}_{4} \cdot{ }^{15}$

Thus, this work revealed that various propagating species which are in different dissociation states exist in the polymerization of IBVE as well as in that of styrene.

\section{REFERENCES}

1. T. Masuda and T. Higashimura, J. Polym. Sci., Part B, 9, 783 (1971).

2. T. Higashimura and O. Kishiro, J. Polym. Sci., Polym. Chem. Ed., 12, 967 (1974).

3. T. Masuda, M. Sawamoto, and T. Higashimura, Makromol. Chem., 177, 2981 (1976).

4. M. Sawamoto, T. Masuda, and T. Higashimura, Makromol. Chem., 177, 2995 (1976).

5. T. Higashimura, O. Kishiro, and T. Takeda, J. Polym. Sci., Polym. Chem. Ed., 14, 1089 (1976).

6. T. Kunitake, K. Takarabe, and S. Tsugawa, Polym. $J ., 8,363$ (1976).

7. As a review, see T. Higashimura, J. Polym. Sci., Polym. Symp., No. 5671 (1976).

8. T. Masuda and T. Higashimura, J. Macromol. Sci. Chem., A5, 547 (1971).

9. R. E. Buckles and J. P. Yuk, J. Am. Chem. Soc., 75, 5048 (1953).

10. S. Okamura, T. Higashimura, and I. Sakurada, $J$. Polym. Sci., 39, 507 (1959).

11. D. D. Eley and A. W. Richard, Trans. Faraday Soc., 42, 425, 436 (1949).

12. D. D. Eley, F. L. Isack, and C. H. Rochester, J. Chem. Soc. Sect. A, 872 (1968).

13. S. Okamura, N. Kanoh, and T. Higashimura, Makromol. Chem., 47, 19 (1961).

14. T. Higashimura and O. Kishiro, Polym. J., 9, 87 (1977).

15. T. Higashimura, T. Takeda, M. Sawamoto, K. Matsuzaki, and T. Uryu, J. Polym. Sci., Polym. Chem. Ed., 16, 503 (1978). 